\title{
Interprofessional communication in a simulation- based team training session in healthcare: A student perspective
}

\author{
Ingunn Aase ${ }^{* 1}$, Karina Aase ${ }^{1}$, Peter Dieckmann ${ }^{2}$, Conrad Arnfinn Bjørshol ${ }^{3}$, Britt Sætre Hansen ${ }^{1}$ \\ ${ }^{1}$ University of Stavanger, Department of Health Studies, Stavanger, Norway \\ ${ }^{2}$ Danish Institute for Medical Simulation (DIMS), Center for Human Resources, Denmark \\ ${ }^{3}$ Stavanger University Hospital, Department of Anaesthesiology and Intensive Care, University of Bergen, Department of Clinical \\ Medicine, Norway
}

Received: November 9, 2015

Accepted: January 29, 2016

Online Published: March 10, 2016

DOI: $10.5430 /$ jnep.v6n7p91

URL: http://dx.doi.org/10.5430/jnep.v6n7p91

\begin{abstract}
Background: Interprofessional teamwork and communication training have entered the healthcare education setting, mainly investigated through surveys. However, little is known about the student's perceptions in more depth. The aim of the study was to investigate healthcare students' perspectives and attitudes towards interprofessional communication in a simulation-based training session.

Methods: The study was designed as an explorative case study based on qualitative content analysis. Data was based on observation of two simulation scenarios ("Internal Bleeding", "Huddle") and analysis of debriefing sessions with a sample of 48 nursing and medical students in Norway. The study was conducted in May 2013.

Results: We found that interprofessional communication was characterized by two main features: clinical exchange and collaborative exchange. While clinical exchange is "objective" and dependent upon clinical information, clinical skills, and standardized tools and procedures (e.g. SBAR), collaborative exchange is less "formal" and relies on dialogue, cross-disciplinary knowledge and role identity. Students seem to direct most of their attention to clinical exchange, while the patient perspective seems less explicit in the training session.

Conclusion: Exploring the student perspective of interprofessional communication has the following implications for the design and implementation of simulation-based training sessions: (a) to balance clinical exchange and collaborative exchange, (b) to introduce patient-centered exchange, and (c) to contextualize standardized communication tools such as SBAR.
\end{abstract}

Key Words: Interprofessional communication, Nursing student, Medical student, Simulation, Debrief, Content analysis

\section{INTRODUCTION}

There is a growing consensus that interprofessional teamwork is crucial for fostering healthcare performance and for minimizing adverse events. ${ }^{[1-8]}$ Against the backdrop of complex clinical procedures, teamwork is believed to play a key role in preventing adverse events by means of sound communication, leadership, workflow, and awareness of risks. ${ }^{[3]}$ Following this, healthcare providers adopt different training efforts to ensure that teams are working and communicating according to predefined protocols. One such effort is Norway.

*Correspondence: Ingunn Aase; Email: ingunn.aase@uis.no; Address: University of Stavanger, Department of Health Studies, NO 4036 Stavanger, 
the deployment of critical event training and simulation, using standardized communication protocols. ${ }^{[9]}$ The focus on stringent communication has generated several new tools, including the situational briefing tool SBAR (Situation, Background, Assessment and Recommendation - is designed to function as a checklist and to structure the team's exchange of information $\left.{ }^{[10]}\right)$. Marshall et al..$^{[1]]}$ and others have published compelling evidence in favor of SBAR, stating that using a structured method improves communication such as a telephone referral in a simulated clinical setting.

\subsection{Background}

As part of the training efforts, several authors point to the benefits of interprofessional team training ${ }^{[12-14]}$ by documenting positive effects on attitudes and knowledge as well as improved team performance and patient care after simulation training.

Other researchers, however, have cast doubt on the costeffectiveness of such efforts and questioned the clinical and patient outcomes of the training, asserting that the research is not yet conclusive. ${ }^{[15,16]}$ One reason might be biases; when asked immediately after a training session, participants are inclined to overrate its value. After reviewing the literature, McCulloch et al. ${ }^{[15]}$ conclude that there is some evidence for training interventions targeted at improving teamwork.

Interprofessional teamwork training efforts have entered the healthcare education setting under the heading of interprofessional education (IPE) ${ }^{[7]}$ To date, the student perspective on interprofessional communication and teamwork has been investigated mainly through pre- and post-training surveys. ${ }^{[4]}$ In this study, we wanted to explore the students' perceptions in more depth, and carried out observations and analysed debrief conversations in a simulation-based training session for nursing and medical students. The study is set in Norway where the Ministry of Education has instructed educational institutions to include interprofessional team training as part of the nursing and medical education. ${ }^{[17]}$ To develop effective interprofessional training sessions, we surmise that the perspectives of the users (i.e. the students) constitute an important source of information.

\subsection{The study aim}

Against this backdrop, the present study aims at describing the student perspective on interprofessional communication, in order to improve the design of future interprofessional teamwork training efforts. In particular, we wanted to investigate the students' perceptions of standardized communication tools such as SBAR. The following research questions have guided this study:

(1) What characterizes interprofessional communication among nursing and medical students in a simulationbased training session and how do students describe it?

(2) How do nursing and medical students perceive the use of SBAR in a simulation-based training session?

\section{METHODS}

The study is designed as a qualitative exploratory case study. ${ }^{[18]}$ The case is defined as the interprofessional training session with participants from a Norwegian nursing faculty and medical faculty. The exploratory case study is seen as a suitable design for gaining in-depth knowledge of a littleknown phenomenon. The phenomenon under study here is interprofessional communication among nursing and medical students and the students' experiences with a structured communication tool.

\subsection{Case context: A simulation-based training session}

The simulation-based training session for interprofessional communication was designed based on standard simulation principles using preparation, demonstration, briefing, simulation, and debriefing as the main phases. ${ }^{[19]}$ The training session was designed according to two simulation scenarios: "Internal Bleeding" (S1) and "The Huddle" (S2). All student groups conducted both scenarios. Table 1 displays the key components of the training session, including pre- and post-simulation activities.

The booklet given to the students prior to the training session was developed by an interprofessional group consisting of a medical doctor, a nurse, and a researcher (first author). An extended interprofessional group designed the training session, recruited the students, and conducted the SBAR demonstration. The facilitators - a physician in S1 and a nurse in S2 were experienced clinicians in emergency medicine (S1) and surgical care (S2).

In the $\mathrm{S} 1$ scenario, the internal bleeding, the clinical observation elaborated that a female patient who has just undergone laparoscopic surgery for removal of ovarian cysts, felt cold and complained about increasing pain (simulation briefing). Later, the patient - represented by a manikin (SimManTM, Laerdal, Stavanger, Norway) - showed additional symptoms indicating internal bleeding and an increasing degree of hypovolemia (during simulation), after which the scenario should ensue with diagnosis and treatment. In the briefing prior to the simulation, in addition to informing the student groups about the patient conditions, equipment, and facilities, the student groups were encouraged to use SBAR.

The S2 scenario, the huddle, emulated events occurring during the meeting arranged prior to daily ward round. The 
facilitator acting as a "night nurse" briefly reported the status of three patients. The student groups were expected to plan the ward round, when shortly after, another nurse reported that the condition of one of the patients was deteriorating. Requested to use SBAR, the student group had to organize appropriate interventions.

Table 1. Key components of the simulation-based training session

\begin{tabular}{|c|c|c|c|}
\hline Training component & Timing & Contents & Purpose \\
\hline Booklet to the students & $\begin{array}{l}\text { One week prior to the } \\
\text { training session }\end{array}$ & $\begin{array}{l}\text { Introduction to SBAR, and } \\
\text { interprofessional teamwork }\end{array}$ & $\begin{array}{l}\text { Introduce the students to the main } \\
\text { purpose of the training session }\end{array}$ \\
\hline Demonstration of SBAR & $\begin{array}{l}\text { At the start of the training } \\
\text { session (15 minutes) in } \\
\text { plenary }\end{array}$ & $\begin{array}{l}\text { Two facilitators - a nurse and a physician - } \\
\text { role-played a poorly conducted SBAR } \\
\text { conversation followed by a best practice } \\
\text { SBAR conversation }\end{array}$ & $\begin{array}{l}\text { Raise the students' awareness of SBAR } \\
\text { and how to conduct it, and develop a } \\
\text { representation of the learning goals }\end{array}$ \\
\hline $\begin{array}{l}\text { Simulation briefing related } \\
\text { to facilities and equipment } \\
\text { for the two scenarios }\end{array}$ & 20 minutes & $\begin{array}{l}\text { To familiarize the student groups with the } \\
\text { simulation setting }\end{array}$ & $\begin{array}{l}\text { Ensure that students are familiar with } \\
\text { the simulation setting and how to use the } \\
\text { simulator as a technical device }\end{array}$ \\
\hline $\begin{array}{l}\text { Scenario briefing related to } \\
\text { patient conditions and } \\
\text { logistics for the two } \\
\text { scenarios respectively }\end{array}$ & 5 minutes & $\begin{array}{l}\text { To familiarize the student groups with the } \\
\text { scenarios and the SBAR tool }\end{array}$ & $\begin{array}{l}\text { Ensure that students are familiar with } \\
\text { the patient case(s) in the scenarios, and } \\
\text { that they are aware of SBAR }\end{array}$ \\
\hline $\begin{array}{l}\text { Simulation, "Internal } \\
\text { bleeding” (S1) or "Huddle" } \\
\text { (S2) }\end{array}$ & $15-20$ minutes & $\begin{array}{l}\text { A facilitator ( physician in } \mathrm{S} 1 \text { and nurse in } \\
\text { S2) supervised the interprofessional } \\
\text { student groups through the simulation }\end{array}$ & $\begin{array}{l}\text { To conduct the scenario according to } \\
\text { best practice as layed out in preparation, } \\
\text { demonstration, and briefing; and to } \\
\text { create a common experience episode } \\
\text { that can be debriefed later }\end{array}$ \\
\hline $\begin{array}{l}\text { Debrief related to } \\
\text { interprofessional } \\
\text { communication for S1 and } \\
\text { S2 respectively }\end{array}$ & 20-45 minutes & $\begin{array}{l}\text { The facilitators steered the group } \\
\text { conversations to capture learning points } \\
\text { and consider improvements }\end{array}$ & $\begin{array}{l}\text { To inspire the students to discuss and } \\
\text { reflect upon interprofessional } \\
\text { communication and the use of SBAR }\end{array}$ \\
\hline
\end{tabular}

During the simulation and ensuing debrief, the facilitators supervised the student groups in each scenario, mainly to ensure that the students covered the pre-defined learning outcomes related to interprofessional communication and SBAR. The 20- to 45-minute debrief sessions were designed to stimulate interprofessional reflection and discussion in a semi-formal setting. ${ }^{[19-21]}$ The facilitators could ask questions about challenges in conducting the scenario, using the SBAR, and student communication, and to ensure that all students participated in the discussion.

\subsection{Participants and data collection}

Over a two-day period in May 2013 a total of 48 students (8 groups) conducted 16 simulations (S1 and S2). Each group had 3-4 medical students (Faculty of Medicine, university 1) and 2-3 nursing students (Nursing School, university 2), a total of 5-7 students in each group. The nursing and medical students were in their third and fourth year, respectively; at a stage where they were expected to have had some experience with interprofessional communication in clinical work. Medical students assumed the role of physicians and nursing students assumed the role of nurses in charge of the patient. Two or three students were observers and the observer role rotated between students in each scenario. A total of 26

Published by Sciedu Press medical students (16 female and 10 male, age range: 20 - 30 years) and 22 nursing students (19 female and 3 male, age range: 20 - 45) participated in the study.

The debrief sessions constituted the main data material of the study. Debrief sessions were audiotaped. Moreover, the first and last authors were observers, taking field notes according to an open observation guide addressing topics such as communication patterns, roles, leadership and responsibility. Field notes were collected during the simulation and the researchers consulted the notes during data analysis.

\subsection{Ethical approval}

The study was approved by the two universities (medicine faculty, university 1 and nursing school, university 2), the hospital in which the students were enrolled in their practice periods, and the Norwegian Social Science Data Service (NSD) (No34416). All participants were informed of the objective of the study and that they were free to participate or withdraw from the study at any point without any negative consequences. Participants gave written consent to be involved in the study and for the debriefing sessions to be audio-recorded. All data were coded to prevent person identification. 


\subsection{Data analysis}

The data consisted of transcribed audio recorded files of the debrief sessions (138 pages), in addition to transcribed field observation notes ( 8 pages). The transcribed debrief data was subjected to content analysis to conceptualize the perspectives of the students. ${ }^{[22,23]}$ The content analysis progressed inductively from meaning units to categories and themes. Following Graneheim and Lundman, ${ }^{[23]}$ Miles and Huberman $^{[24]}$ and Polit and Beck ${ }^{[22]}$ a latent analysis at an interpretative level was performed by the authors in order to ensure a broad and valid analysis of the data. Table 2 displays the analytical steps from condensed meaning units to categories to theme for one of the main themes, collaborative exchange. The analysis was inductive in the sense that the main themes were distilled from data rather than adapted to established theories. Field observation notes were used as a basis for the descriptive parts of the results, explaining how the interprofessional communication proceeded in the simulations.

Table 2. Collaborative exchange: The analytical process relating meaning units to condensed meaning units, categories and theme

\begin{tabular}{|c|c|c|c|}
\hline Theme & Collaborative exchange & & \\
\hline Categories & Team dialogue & Cross-disciplinary knowledge & Identity and roles \\
\hline Condensed meaning units & $\begin{array}{l}\text { Chatting and asking each other } \\
\text { questions }\end{array}$ & No knowledge of nursing tasks & $\begin{array}{l}\text { Nurses are anxious when } \\
\text { calling the physician }\end{array}$ \\
\hline Meaning units & $\begin{array}{l}\text { I found it very useful that both } \\
\text { student groups [nursing, medical } \\
\text { students] chatted and asked each } \\
\text { other questions and that the } \\
\text { dialogue bounced back and forth }\end{array}$ & $\begin{array}{l}\text { I had no idea what the nurses are } \\
\text { doing, I would like to know more } \\
\text { about it, though }\end{array}$ & $\begin{array}{l}\text { I feel anxious when calling } \\
\text { the physician, but the } \\
\text { feeling tends to diminish } \\
\text { after a while, especially } \\
\text { when you have a checklist } \\
\text { to guide you }\end{array}$ \\
\hline
\end{tabular}

All data were jointly coded by the authors IA and BSH, and any disagreements were solved through discussions with author KA.

\section{RESUlts}

By observing and analyzing interprofessional communication between nursing and medical students in a simulationbased team training session, we have identified differences in communication related to how students perceive the exchange of clinical information (research question 1), the team dialogue (research question 1), and the use of standardized communication (SBAR) (research question 2). In the following, we will present our findings under the two main themes of clinical and collaborative exchange as features of interprofessional communication amongst nursing and medical students.

\subsection{Clinical exchange}

The perspective of clinical exchange reflects the prevailing view of healthcare treatment and care as dependent on precise clinical information. In conducting the simulation scenarios and in the debrief sessions, students seem to direct their attention towards clinical information, also solicited by the simulation facilitators. The students tightly linked clinical information to medical treatment and "vital signs", conceptualizing the patient from the position of an external observer, emphasizing physiological and quantitative information needed to "repair" and "control" the patient. In the simulation scenarios, the clinical information conveyed measures of blood pressure, body temperature, heart frequency, etc. In addition, the SBAR-procedure was categorized as clinical information due to its focus on clinical parameters such as blood pressure, heart rate, body temperature and respiration rate. As a matter of terminology, the students often used the term "parameters" interchangeably with clinical data measured and maintained by the nurses, who used paper-based data sheets.

Cognizant that miscommunication could lead to patient injuries, many students emphasized the need for accurate clinical information exchange. Still, the debrief data unveiled examples of insufficient and misunderstood clinical communication. The medical students were persuaded to attribute communication failures to the nursing students' supposed inaccuracy and evasiveness. As one medical student complained:

I dislike when the nursing students excuse themselves; I want concise and accurate information. (Medical student, S1)

Another medical student stated:

I tried to ask specific questions that could be responded in a clear manner. If the nurse has not 
measured CRP (C-reactive protein) it is better to just say so. If she starts to defend herself, it takes too much time. (Medical student, S1)

The following dialogue presents another shortcoming of clinical communication:

I did not know that the patient had been in good shape only ten minutes earlier. The nursing student should have expressed this important information more clearly. (Medical Student, S1)

Yes, I should have mentioned this, but it did not strike me at the time (Nursing student, S1)

I should have asked you; I guess we are both to blame. (Medical student, S1)

Obstacles to clinical communication were frequently but not always rooted in professional and hierarchical differences, meaning that nursing and medical students have different understandings of work tasks and priorities and that nursing students look at medical students as higher in the hierarchy. The debrief data showed that nursing students sometimes found it difficult to comprehend the report delivered by an experienced "night-nurse" at the start of the simulations. The reasons were related mainly to time constraints.

Closely linked to the clinical exchange is the use of standardized communication tools, in this case SBAR and a paper-based data sheet hosting the "parameters". The use of SBAR varied from one simulation group to another and the communication tool was only partly exploited (observations, $\mathrm{S} 1, \mathrm{~S} 2$ ). The variations pertained to the degree of SBAR use, and to the SBAR elements that were in use. In one group the students never attempted to utilize SBAR at all, even if this was one of the objectives of the simulation. When asked whether they had thought of using SBAR they responded as follows:

No, I did not (Nursing student 1, S2)

Neither did I (Nursing student 2, S2)

I thought about it briefly, but I did not feel we had so much to say to each other (Medical student, S2)

Others found the SBAR too complicated to use:

I could not remember all the sub-headings of SBAR, but I believe I got through with the most important ones. It is useful because it forces you to systemize your thoughts. (Medical student, S1)

Even when SBAR was successfully adopted, there were still mistakes and misunderstandings. In a potentially adverse

Published by Sciedu Press incident the identity of two patients was mixed. A patient referred to as "number 2" was in fact not as such on the list of patients, however, she occupied bed No 2 (Observation, S2). In the following debrief the error was discussed and the students tried to explain the situation by referring to it as "something that can happen".

The following dialogue underscored the student perceptions of benefits and challenges with using SBAR as part of the clinical exchange:

My first reaction was that I will never be able to remember all the 20 points, but the four major SBAR points I can manage. I feel it is okay to relate four such points... It may be an issue of training, it is good to follow a logical sequence. (Medical Student, S1)

Yes, it is good to have, because when I am stressed there are many things floating around in my head. With SBAR I experience a sense of control, even if I may not have it, but I have at least some control of what to tell the physician, in a clear and concise manner. (Nursing student, S1)

Other students emphasized that the SBAR formalism should be attuned and downscaled to suit the situation at hand:

It is useful, but at first we thought it was impossible to remember like 120 points, but then 4 key points are okay, the rest we can we find on the data sheet. (Nursing student, S2).

We won't always follow it; it depends on the problem. If the patient for example suffers a simple injury to his foot, SBAR is too complex. But we can properly use it in most cases - of course it depends on whether the other team members know the patient or not. (Medical student, S2)

The students' perspectives of the patient in the simulation scenarios was difficult to grasp in data pertaining to both observations and debrief sessions. Interwoven and latent, the issue sometimes surfaced in statements related to clinical information:

I felt I needed new data [the parameters], but I did not want to ask the nurses. I find it hard to ask them to leave the meeting for acquiring the parameters. (Medical student, S2)

You should have asked; we are here for the patients. (Nursing student, S2)

In another situation, a nursing student expressed a desire for clinical information to pass on to the patient: 
I got information from the physicians, regarding what X-ray they were planning to obtain, which turned out to be a chest X-ray. It was good to know since I then could tell the patient what would happen. (Nursing student, S1)

\subsection{Collaborative exchange}

The perspective of collaborative exchange reflects the view of healthcare treatment and care as dependent on team efforts and interprofessional communication. While the students often understood the communication associated with clinical exchange as instructions, they saw collaborative exchange as an invitation to discuss in order to reach consensus on the actions taken by the student group in the simulation scenarios. This included a more general and less formal dialogue among student group members than the one associated with clinical information. Data belonging to the theme of collaborative exchange were predominantly linked to the simulation scenario S2 ("The Huddle"). It is possible that the S2 scenario in itself was designed as a planning and communication arena.

Maintaining a broad team dialogue that might sometimes spill over in informal chatting was perceived as a fundamental feature of successful interprofessional communication in the simulation scenarios. The contents of the dialogue, the form, and the "tone" of the dialogue were seen as vital components of collaborative exchange as exemplified by the following conversation:

I found it very useful that both student groups [nursing, medical students] chatted and asked each other questions and that the dialogue bounced back and forth. (Medical student, S2)

We may have been a bit unstructured. (Nursing student, S2)

Students reflected on instances where lack of dialogue impaired team performance. Unaware that the nursing student had just checked the patient, a medical student examined the patient himself. During the following debrief the participants explained the situation:

I wanted to see the patient myself. (Medical student, S2)

Yes, but if the patient was unconscious, it would have been the first thing I told you. (Nursing student, S2)

Oh yes, we must ask each other more often. (Medical student, S2)

In some instances the medical students - out of politeness or concern for the nursing students refrained from asking them questions. A nursing student emphasized that the nurses' data and measurement was not always updated, and that 96 if the measurements have not been obtained, the physician should not be afraid of asking. (Nursing student, S2)

The interprofessional dialogues between nursing and medical students in the simulation scenarios, and in the debrief sessions documented the importance of chatting, trust, frankness and information relevance for the collaborative exchange to be effective. In these informal team dialogues clinical exchange was often embedded indirectly by reference to, for example, the measured "parameters". In the same vein, the patient perspective in some occasions could be referred to in the team dialogues. As one nursing student stated:

We should have discussed this together. We are supposed to improve the situation for the patient. (Nursing Student, S2)

The effectiveness of the collaborative exchange also seemed to rely on a minimum of cross-disciplinary knowledge across nursing and medical students involved in team training. In the current training session context, this requirement seemed flawed. Medical students expressed concerns that a lack of knowledge regarding the nursing tasks and practices could hamper the team dialogue. A medical student conceded that

I had no idea what the nurses are doing, I would like to know more about it, though. (Medical student, S2)

Another medical student stated that:

I was unaware of the nurses' time schedule and workload, the patient to nurse ratio, etc. (Medical student, S2)

In contrast, nursing students were inclined to overrate the medical students' insights into the practical aspects of nursing, and found it difficult to accept that the medical students were unfamiliar with the graphs and datasheets maintained by the nurses. Some of the medical students did not even know that the nurses maintained such data sheets. A medical student conceded that

I did not know that a data sheet with background information existed. (Medical Student, S2).

The lack of cross-disciplinary knowledge also seemed to be reinforced by professional boundaries related to identity and roles indicating uncertainty and traditional role hierarchy. A nursing student remarked:

I was also certain that it was an intraabdominal bleeding, but I did not dare to say it because it is the physicians who make the diagnoses. (Nursing student, S1)

ISSN 1925-4040 E-ISSN 1925-4059 
Some of the nursing student admitted feeling uncertain and afraid when calling a physician. As one student stated:

I feel anxious when calling the physician, but the feeling tends to diminish after a while, especially when you have a checklist to guide you. (Nursing student, S1)

Not wanting to be intimidated, some medical students expressed similar concerns regarding contacting more experienced colleagues, usually physicians, but occasionally nurses. Planning and discussion tended to happen in parallels in nursing and medical student sub-groups respectively, rather than across disciplines. A nursing student explained:

When we received the report of the night nurse, I said that if you care for patient number 1, I will attend to the two other patients. So we nurses had already organized a little, but we knew nothing about the physicians. I assumed they had their own system. (Nursing student, S2)

\section{Discussion}

In this study we have established the characteristics of interprofessional communication among nursing and medical students in a simulation-based training session analyzed according to the two themes of clinical exchange and collaborative exchange. The two themes are interrelated but also hold unique characteristics. While clinical exchange is "objective" and dependent upon clinical information, clinical skills, and standardized tools and procedures (e.g. SBAR), collaborative exchange is less "formal" and relies on dialogue, crossdisciplinary knowledge and role identity. Students seem to direct most of their attention towards clinical exchange while still valuing the more informal dialogue and discussion elements of collaborative exchange. The patient perspective seems less explicit in the training session as observed in the simulation scenarios and in the debrief sessions. Overall, focusing on the students' perspectives of interprofessional communication has several implications for the design and implementation of simulation-based training sessions across the nursing and medicine specialties. Below we will address the most vital issues.

\subsection{Balancing clinical exchange and collaborative ex- change}

In the reported study the current training session contained two simulation scenarios, Internal Bleeding and the Huddle, facilitated by an experienced emergency medicine physician and an experienced surgical care nurse, respectively. It was perhaps inevitable that interprofessional communication in

Published by Sciedu Press the Internal Bleeding scenario and debrief was characterized by clinical exchange while communication in the Huddle scenario and debrief was focused on collaborative exchange. A recent study of different stakeholder groups' (students, university faculty, hospital staff) views on interprofessional training in the same Norwegian case context found similar requirements for balancing clinical professionalism (clinical exchange) and team performance (collaborative exchange) contingent on the students' background and the learning objectives. ${ }^{[25]}$ Stakeholders furthermore voiced concerns related to how communication issues, collaboration and workflow could be reflected in interprofessional training. This indicates that training elements pertaining to collaborative exchange might be more challenging to design and require different simulation scenarios from the acute setting traditionally used in most healthcare training efforts. ${ }^{[26,27]}$

Fostering collaborative exchange in the training session requires some generic principles among the students such as trust and cross-disciplinary knowledge. Our analysis unveiled that communication within the student groups was obscured by a lack of such cross-disciplinary knowledge. On the one hand, medical students' understanding of nursing and nursing capabilities revealed gaps. Nursing students on the other hand revealed attitudes that distorted their ability to "speak up". Previous research within simulation-based team training has documented a positive effect of "speaking up" on team performance. ${ }^{[28]}$

The issue of "being afraid of each other" as displayed in the study results may refer to traditional patterns of professional roles still prevalent in health care teams, ${ }^{[29]}$ influencing the participants' predisposition to communicate freely and share responsibility, both of which are the pillars of teamwork. ${ }^{[30]}$ Healthcare education must thus ensure that students practice in an environment where they reach their full potential, ${ }^{[31]}$ meaning that nursing students should be prepared to work in ways that prepare them for clinical decision making and that medical students should increase their knowledge level of nurses' competencies.

To be able to tailor for these basic principles the role of the facilitators becomes crucial. ${ }^{[32,33]}$ In our study the Internal Bleeding scenario was facilitated by an experienced emergency medical physician and the Huddle scenario by an experienced surgical care nurse. Uni-professional facilitation might run the risk of protecting already existing role identity and behavior amongst the students. It might therefore be beneficial in future training efforts to test interprofessional facilitator teams (nurse, physician) and their effect on interprofessional communication among students. 


\subsection{Introducing patient-centered exchange}

Introducing patient-centered exchange in interprofessional training implies that participants (students, healthcare staff) would identify with the patient as the center of attention. The patient perspective has received abundant attention in the literature ${ }^{[34,35]}$ understood communication-wise as lending a voice to the patient and speaking on his/her behalf. In the observed simulation scenarios and debrief sessions patient-centered exchange was not a salient characteristic of the interprofessional communication in the student groups. Although the patient's interests were brought up regularly by the nursing students - and sometimes by the medical students - patient-centered exchange was often latent and partly interwoven in the clinical exchange or the collaborative exchange. One reason for the latent presence of patientcentered exchange in the training session might be that "real" patients were not present in the simulation scenarios. The Internal Bleeding scenario used a manikin while in the Huddle scenario imaginary patients were discussed in the preward round meeting. To better introduce patient-centered exchange as part of interprofessional simulation-based training, the use of standardized patient (SP)/ or role-plays (lowfidelity) including patients should be considered. ${ }^{[36]}$

\subsection{Contextualising standardized communication tools}

While the students in the current study were generally supportive of the standardized SBAR format, the student groups clearly struggled with applying the communication tool to it's full extent, suggesting the protocol should be simplified and attuned to the situation at hand. SBAR being developed for structured communication in acute setting ${ }^{[10]}$ needs to be contextualized to the clinical situation at hand or as one of the students eloquently formulated it: "It depends on the problem". In fact, some student groups have already embarked on a strategy of SBAR modification during the simulation session.

Furthermore, the attempt to introduce SBAR by providing a brief theoretical introduction with instructions for the students to follow the procedure, failed to encourage use of the communication tool. This suggests that SBAR should be introduced using a more extensive process, preferably by prolonging the training. This finding resonates with the results discussed by McCulloch et al., ${ }^{[15]}$ advocating for a higher intensity of training interventions such as the SBAR tool.

\subsection{Limitations}

Designed as an explorative case study with a limited sample of 48 students and two simulation scenarios, the implications of this study should be interpreted with caution. Nevertheless, the lack of in-depth knowledge of the student perspective on interprofessional communication warrants the importance of the study results which should form an important basis for broader implementation studies of interprofessional student training.

The use of single uni-professional facilitators in the simulation scenarios and the following debrief sessions might have affected the students' behavior, openness, and opinions of interprofessional communication. For future training efforts we would therefore suggest interprofessional facilitator teams.

In observing the simulation scenarios and the debrief sessions observer bias might have affected the data collected. ${ }^{[18,20]}$ This was compensated for by using two experienced observers following an agreed-upon observation guide, and by following an extensive collaborative approach amongst three of the authors in analyzing the data.

The students had only one day with simulation-based training in interprofessional communication, meaning that the results could have been different if the training been conducted regularly throughout their study period.

\section{Conclusion}

By observing and analyzing a simulation-based training session for nursing and medical students, we have shown that the interprofessional communication can be characterized using clinical exchange and collaborative exchange. Patientcentered exchange was latent and largely missing in the communication. We surmise that effective interprofessional communication training amongst healthcare students relies on balancing issues of clinical exchange and collaborative exchange and at the same time introducing more traits of patient-centered exchange in the training.

The use of standardized communication tools in interprofessional training seems to be highly related to clinical exchange. Using SBAR in the current study was only partly successful according to the students who requested modifications of the protocol to suit the situation and the complexity at hand.

\section{ACKNOWLEDGEMENTS}

We thank the students and the facilitators for their helpful responses and participation in the study. This study was accomplished with financial support from the Laerdal Foundation for Acute Medicine under the support number 1007. 


\section{REFERENCES}

[1] Clark PG. Examining the interface between interprofessional practice and education: Lessons learned from Norway for promoting teamwork. Journal of Interprofessional Care. 2011; 25(1): 26-32. PMid:20795829 http://dx.doi.org/10.3109/1356182 0.2010 .497751

[2] Clark PG. The devil is in the details: The seven deadly sins of organizing and continuing interprofessional education in the US. Journal of Interprofessional Care. 2011; 25(5): 321-327. PMid:21823881 http://dx.doi.org/10.3109/13561820.2011.578223

[3] Manser T. Teamwork and patient safety in dynamic domains of healthcare. A review of the literature. Acta Anesthesiology Scandinavia. 2009; 53: 143-151. PMid:19032571 http://dx.doi.org/10.11 $11 / \mathrm{j} .1399-6576.2008 .01717 . \mathrm{x}$

[4] Reeves S, Lewin S, Espin S, et al. Interprofessional teamwork for health and social care. 2010. Wiley-Blackwell, UK.

[5] Zwarenstein M, Reeves S. Knowledge translation and interprofessional collaboration: Where the rubber of evidence based care hits the road of teamwork. Journal of Continuing Education in the Health Professions. 2006; 26: 46-54. PMid:16557506 http: //dx.doi.org/10.1002/chp.50

[6] Zwarenstein M, Goldman J, Reeves S. Interprofessional collaboration: Effects of practice-based interventions on professional practice and healthcare outcomes (Review). 2009. The Cochrane Collaboration.

[7] World Health Organization (WHO) Framework for action on IPE \& collaborative practice, Switzerland S \& B Graphic Design. 2010.

[8] World Health Organization (WHO) Patient Safety Curriculum Guide Multi-professional Edition, Switzerland S \& B Graphic Design. 2011. ISBN 9789241501958.

[9] Leonard M, Graham B, Bonacum D. The human factor: The critical importance of effective teamwork and communication in providing safe care. Quality \& Safety In Health Care. 2004; 13 (1): 85-90.

[10] Haig K, Sutton S, Whittington J. SBAR: A shared mental model for improving communication between clinicians. Joint Commission Journal on Quality and Patient Safety. 2006; 32: 167-175.

[11] Marshall S, Harrison J, Flanagan B. The teaching of a structured tool improves the clarity and content of interprofessional communication. Qual Saf Health Care. 2009; 18: 137-140. PMid:19342529 http://dx.doi.org/10.1136/qshc.2007.025247

[12] Brock D, Abu-Rish E, Chiu CR, et al. Interprofessional education in team communication: Working together to improve patient safety. BMJ Quality and Safety in Health Care. 2013: 1-10. http://dx.doi.org/10.1136/bmjqs-2012-000952

[13] Capella J, Smith S, Philp A, et al. Teamwork training improves the clinical care of trauma patients. Journal of Surgical Education. 2010: 439-443. http://dx.doi.org/10.1016/j.j surg. 2010. 06.006

[14] Garbee D, Paige J, Barrier K, et al. Interprofessional teamwork among students in simulated codes: A quasi-experimental study. Nursing Education Perspectives. 2013; 34(5): 339-344.

[15] McCulloch P, Rathbone J, Catchpole K. Interventions to improve teamwork and communications among health staff. Systematic review. British Journal of Surgery Society. 2011; 98: 469-479. PMid:21305537 http://dx.doi .org/10.1002/bjs. 7434

[16] Schmutz J, Manser T. Do team processes really have an effect on clinical performance? A systematic literature review. British Journal of Anaesthesia. 2013; 110(4): 529-544. http://dx.doi.org/10. 1093/bja/aes513

[17] White Paper 13. Norwegian Ministry of Education and Research: Meld. St. No. 13 (2012-2013) Utdanning for velferd. Samspill i prak- sis (Education for welfare. Cooperation in practice.) Governmental White Paper.

[18] Yin RK. Case Study Research. Design and Methods. 2014; Sage Publications: California.

[19] Dieckmann P. Using simulations for educations, training and research. 2009; Pabst Science Publishers, Lengerich. ISBN 978-3-89967-5399.

[20] Fanning RM, Gaba DM. The role of debriefing in simulation- based learning. Society for Simulation in Healthcare. 2007; 2(2): 115-125. http://dx.doi.org/10.1097/SIH. Ob013e3180315539

[21] Flanagan B. Debriefing: Theory and technique. In R.H. Riley (Ed.), Manual of simulation in healthcare. 2008; OUP Oxford, Oxford. 155-170.

[22] Polit DF, Beck CT. Nursing research: Generating and assessing evidence for nursing practice. 2012. Lippincott Williams \& Wilkins, Philadelphia.

[23] Graneheim UH, Lundman B. Qualitative content analysis in nursing research: Concepts, procedures and measures to achieve trustworthiness. Nurse Education Today. 2004; 24(2): 105-12. PMid:14769454 http://dx.doi.org/10.1016/j.nedt.2003.10.001

[24] Miles MB, Huberman AM. Qualitative Data Analysis. 1994. Sage Publications, Thousand Oaks, CA.

[25] Aase I, Hansen BS, Aase K, et al. Interprofessional training for nursing and medical students in Norway: Exploring different professional perspectives. Journal of Interprofessional Care. 2015. http: //dx.doi.org/10.3109/13561820.2015.1054478

[26] Bandali K, Parker K, Mummery M, et al. Skills integration in a simulated and interprofessional environment: An innovative undergraduate applied health curriculum. Journal of Interprofessional Care. 2008; 22(2): 177-189.

[27] IOM (Institute of Medicine) Measuring the Impact of Interprofessional Education on Collaborative Practice and Patient Outcomes. 2015; The National Academies Press, Washington DC.

[28] Kolbe M, Burtscher MJ, Wacker J, et al. Speaking up is related to better team performance in simulated anesthesia inductions: An observational study. Zurich Open Repository. and Archive. 2012; University of Zurich. http://dx . doi .org/10.5167/uzh-65917

[29] Aase I, Hansen BS, Aase K. Norwegian nursing and medical students' perception of interprofessional teamwork: A qualitative study BMC Medical Education. 2014; 14: 170-179. PMid:25124090 http://dx.doi.org/10.1186/1472-6920-14-170

[30] Chapelain P, Morineau T, Gautier C. Effects of communication on the performance of nursing students during the simulation of an emergency situation. Journal of Advanced Nursing. 2015; 71(11): 2650-2660. http://dx.doi.org/10.1111/jan.12733

[31] Fawcett TN, Holloway A, Rhynas S. Editorial: If I have seen further it is by standing on the shoulders of giants: Finding a voice, a positive future for nursing. Journal of Advanced Nursing. 2015; 71(6): 1195-1197. PMid:25376256 http://dx.doi.org/10.1111/jan .12556

[32] Thomas L, Reeves S. Sociological fidelity: Keeping the patient at the heart of interprofessional learning. Journal of Interprofessional Care. 2015; 29(3): 177-178. PMid:25909446 http://dx.doi .org/10. $3109 / 13561820.2015 .1035179$

[33] van Soeren M, Devlin-Cop S, MacMillan K, et al. Simulated interprofessional education: An analysis of teaching and learning processes. Journal of Interprofessional Care. 2011; 25 (6): 434440. PMid:21899398 http://dx.doi.org/10.3109/13561820. 2011.592229

[34] Mead N, Bower P. Patient-centred consultation and outcomes in primary care: A review of the literature. Patient Education and Coun- 
seling. 2002; 48: 51-61. http://dx.doi.org/10.1016/S0738 -3991 (02) 00099-X

[35] Storm M, Edwards A. Models of user involvement in the mental health context: Intentions and Implementation Challenges. Psychiatric Quarterly. 2013; 84: 313-329. PMid:23076765 http://dx.d oi.org/10.1007/s11126-012-9247-x

[36] Stocker M, Burmester M, Allen M. Optimisation of simulated team training through the application of learning theories: A debate for a conceptual framework. BMC Medical Education. 2014; 14(69): 1-9. PMid:24387322. 